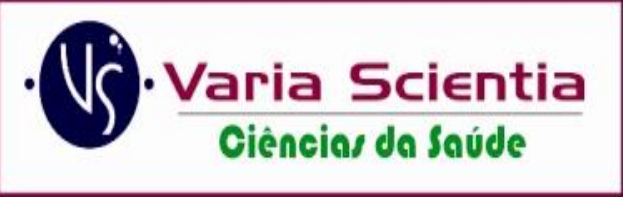

e-ISSN 2446-8118

\title{
REPERCUSSÕES DO TRABALHO DOCENTE NO PROCESSO SAÚDE E DOENÇA DE PROFESSORES DA REDE PÚBLICA ESTADUAL DE ENSINO NO MUNICÍPIO DE CASCAVEL/PR
}

\author{
REPERCUSSIONS OF TEACHER WORK IN THE HEALTH AND DISEASE PROCESS \\ OF TEACHERS THE PUBLIC NETWORK STATE OF TEACHING OF THE MUNICIPLE \\ OF CASCAVEL/PR
}

\section{REPERCUSIONES DEL TRABAJO DOCENTE EN EL PROCESO SALUD Y ENFERMEDAD DE PROFESORES LA RED PÚBLICA ESTADO DE ENSEÑANDO DE LA CIUDAD DE CASCAVEL/PR}

\author{
Terezinha Aparecida Campos ${ }^{1}$ \\ Tania Maria Rechia ${ }^{2}$ \\ Alessandro Rodrigo Zanato ${ }^{3}$
}

\begin{abstract}
RESUMO: Introdução: No intuito de compreender parte do vasto e do complexo universo da saúde e doença é preciso, antes de tudo, humildade para reconhecer que todo é qualquer estudo sobre essa temática é parcial e provisório. É preciso, escolher caminhos e recortes para abordá-lo. Essa contextualização é necessária em razão de que saúde e doença não representam a mesma coisa para as pessoas, pois que diversos fatores podem influenciar a percepção de cada um. Visto que, isso vai depender do contexto em que a pessoa vive, bem como das suas relações sociais, dos seus valores, das suas concepções científicas, religiosas e filosóficas. Objetivo: Conhecer a percepção dos professores que atuam na rede pública estadual de ensino no município de cascavel/PR, sobre o
\end{abstract}

\footnotetext{
${ }^{1}$ Programa de Atendimento Residencial/PAR, Secretaria Municipal de Saúde de Cascavel (SESAU), Cascavel (PR), Brasil e Universidade Estadual do Oeste do Paraná - Unioeste. Graduada em Enfermagem Bacharel e Licenciatura (2009), Pós Graduação em Saúde Pública (2011) Mestrado em Educação (2018) pela Universidade Estadual do Oeste do Paraná (Unioeste). Tem experiência na área de Enfermagem, com ênfase em: Atenção Domiciliar, Saúde Pública, Gerenciamento, Clínica Médico-Cirúrgica, Urgência e Emergência, Unidade de Terapia Intensiva, Atendimento Pré Hospitalar (APH), Ostomias e Feridas. Foi coordenadora de enfermagem na Unidade de Pronto Atendimento - UPA II. Atualmente é preceptora de enfermagem do Programa da Residência Multiprofissional da secretaria municipal de saúde de Cascavel/PR e enfermeira responsável técnica e assistencial no Programa de Atendimento Residencial (PAR).

${ }^{2}$ Universidade Estadual do Oeste do Paraná - Unioeste. Possui graduação em Pedagogia pela Universidade Federal do Paraná (1986), mestrado em Educação pela Unicamp (1998) e doutorado em Educação pela Unicamp (2005). Realizou estágios de pós-doutorado na França com Michel Maffesoli, professor emérito da Universidade de Paris V (Sorbonne), e na Universidade Federal de São Paulo (UNIFESP) pelo Programa Nacional de Pós Doutorado da CAPES PNPD/CAPES. É professora associada da Universidade Estadual do Oeste do Paraná no curso de Pedagogia e no Programa de Pós-graduação em Educação na área de didática e prática de ensino. Em pesquisa vem atuando principalmente nos seguintes temas: didática e formação de professores, juventude; conflitos e violência na escola. É integrante dos grupos de pesquisa IMAGINAR - Grupo de Pesquisas sobre Imaginário, Educação e Formação de Professores e Grupo de Estudos e Pesquisas em Desenvolvimento da Educação Básica (UNIOESTE).

${ }^{3}$ Graduado em História com licenciatura (2003), Psicologia com bacharel (2010) e licenciatura (2012); Psicanalista (2013); possui Mestrado em Educação (2016); Especialização em: Gestão Empresarial (2011); Psicanálise Clínica Freud e Lacan (2012); Dependência Química Álcool e Drogas (2013); Saúde Mental e Atenção Psicossocial (2013); em andamento: Docência do Ensino Superior (2020); Neurociências e Comportamento (2020); Saúde Pública e Saúde da Família (2020). Acadêmico do $9^{\circ}$ Período de Medicina (2020). Atualmente atua como Psicanalista Clinico, Psicoterapia e Analise sob orientação psicanalítica, e Supervisão clínica. Pesquisas em andamento na área da: Educação; Psicologia; Psicanalise; Medicina; Psiquiatria; Saúde mental e Dependências.
} 
processo saúde e doença no cotidiano do trabalho. Métodos: Foi realizado uma pesquisa de campo, de cunho exploratório e qualitativo. Para a coleta de dados foi utilizado um roteiro semiestruturado, aplicado na forma de entrevistas à 15 (quinze) professores. Depois os dados foram agrupados e analisados por meio da Técnica de Análise de Conteúdo. Resultados: Constatou-se que, os professores estão expostos a uma sobrecarga de atividades laborais e $100 \%$ dos entrevistados afirmam que já trabalharam doentes. Logo, as circunstâncias do cotidiano, influência sobremaneira na saúde. Conclusão: Infere-se que, diante do caleidoscópio do processo saúde e doença há características objetivas e subjetivas que extrapola o corpo físico e biológico, afetando sua dimensão mental, social e cultural, perceptíveis nos relatos dos professores, em suas relações em sala da de aula.

DESCRITORES: Processo saúde e doença. Agravos à Saúde. Professores. Percepção. Trabalho Docente. Sala de Aula.

ABSTRACT: Introduction: In order to understand part of the vast and complex universe of health and disease it is necessary, first of all, humility to recognize that any study on this theme is partial and provisional. It is necessary to choose paths and cutouts to approach it. This contextualization is necessary because health and disease do not represent the same thing for people, since several factors can influence the perception of each one. Since, this will depend on the context in which a person lives, as well as on their social relationships, their values, their scientific, religious and philosophical conceptions Objective: To know the perception of teachers who work in the state public school system in the municipality of Cascavel/PR, about the health and disease process in their daily work. Methods: An exploratory and qualitative field research was carried out. For data collection, a semi-structured script was used, applied in the form of interviews to 15 (fifteen) teachers. Then, the data were grouped and analyzed using the Content Analysis Technique Results: It was found that, teachers are exposed to an overload of work activities and $100 \%$ of respondents say that they have already worked sick. Therefore, the circumstances of everyday life, greatly influence health. Conclusion: It is inferred that, before the kaleidoscope of the health and disease process, there are objective and subjective characteristics that go beyond the physical and biological body, affecting its mental, social and cultural dimension, which are noticeable in teachers' reports, in classroom relations.

KEYWORDS: Health and disease process. Health Problems. Teachers. Perception. Teaching Work. Classroom.

RESUMEN: Introducción: Para comprender parte del vasto y complejo universo de la salud y la enfermedad es necesario, ante todo, humildad para reconocer que todo es cualquier estudio sobre este tema es parcial y provisional. Es necesario elegir caminos y recortes para abordarlo. Esta contextualización es necesaria porque la salud y la enfermedad no representan lo mismo para las personas, ya que varios factores pueden influir en la percepción de cada uno. Ya que, esto dependerá del contexto en el que viva la persona, así como de sus relaciones sociales, sus valores, sus concepciones científicas, religiosas y filosóficas. Objetivo: Conocer la percepción de los docentes que trabajan en el sistema escolar público estatal de la ciudad de Cascavel/PR, sobre el proceso de salud y enfermedad en su trabajo diario. Metodologia: Se realizó una investigación de campo exploratoria y cualitativa. Para la recolección de datos se utilizó un guión semiestructurado, aplicado en forma de entrevistas a 15 (quince) docentes. Luego, los datos se agruparon y analizaron mediante la técnica de análisis de contenido. Resultados: Se encontró que, los docentes están expuestos a una sobrecarga de actividades laborales y el $100 \%$ de los encuestados dice que ya ha trabajado enfermo. Por tanto, las circunstancias de la vida cotidiana influyen mucho en la salud. Conclusión: Se infiere que, ante el caleidoscopio del proceso de salud y enfermedad, existen características objetivas y subjetivas que van más allá del cuerpo físico y biológico, afectando su 
dimensión mental, social y cultural, las cuales se notan en los relatos de los docentes. en sus relaciones en el aula.

DESCRIPTORES: Proceso de Salud y Enfermedad. Problemas de Salud. Maestros. Percepción. Trabajo Docente. Aula.

\section{INTRODUÇÃO}

Nos dias atuais a sociedade tem sido marcada por transformações sociais, econômicas, políticas e culturais. Consequentemente, isso leva ao surgimento de novas relações sociais, as quais querendo ou não, transformam significativamente $\mathrm{o}$ cotidiano das pessoas.

Pensando na dinâmica do trabalho docente, as transformações decorrentes da forma como a sociedade se organiza acabam acometendo e alterando, direta e indiretamente, no ser e no fazer docente e, por conseguinte no processo saúde e doença desses profissionais.

Isto posto, é inevitável não olhar para as características de uma sociedade pósmoderna quando se procura compreender o processo de adoecimento, já que as transformações sociais que vêm ocorrendo têm provocado profundas rupturas nos modos de ser e de viver, bem como na percepção de mundo dos sujeitos.

$\mathrm{Na}$ atual conjuntura, há de se convir que o cotidiano dos professores é, na maioria das vezes, marcado pela sobrecarga de trabalho, situação que pode deixá-lo mais suscetível ao adoecimento físico e mental. Uma vez que, a jornada de trabalho do professor não acaba ao tocar o sinal, pois, ao deixar a escola, ele vai para casa levando trabalho extra, como provas e trabalhos para corrigir, diários de classe para preencher, sem mencionar o tempo que ele precisa para preparar as aulas e avaliações posteriors ${ }^{1}$.

Nitidamente, o trabalho exerce um poderio sobre a vida das pessoas e que as mudanças na dinâmica do trabalho, novas ameaças passam a fazer parte da rotina dos professores, os quais estão continuamente à mercê da sobrecarga de trabalho e dos riscos biopsicossociais inerentes às atividades desenvolvidas.
Nessa perspectiva, entende-se que o processo saúde e doença dos professores requer que seja visto sob um prisma que preze as condições nas quais se desempenha a docência. E essa observação necessariamente tem que ser para além do aspecto físico e biológico, pois é uma preocupação que deve ser ponderada a partir do contexto histórico do ser humano.

Pesquisando sobre os impactos que a dinâmica do trabalho pode trazer ao docente, e ao observar empiricamente, enquanto enfermeira, as complicações quanto à saúde desses profissionais, é possível perceber que há uma lacuna entre condições ideais de trabalho e saúde do trabalhador. Tais circunstâncias nos deixam apreensivos e, muitas vezes frustrados, em decorrência do aumento do número de professores afastados por doenças relacionadas ao ambiente de trabalho.

Sendo assim, nota-se a importância de compreendermos o ser humano em sua totalidade, bem como na sua interação com o meio em que vive. No caso dos professores, é importante entender a maneira como esses profissionais percebem o processo saúde e doença no seu cotidiano. Para isso nos indagamos como se expressa, no cotidiano dos professores, o processo de saúde e doença?

Diante do exposto, o escopo deste artigo é conhecer a percepção dos professores que atuam na rede pública estadual de ensino no município de cascavel/PR, sobre o processo de saúde e doença no cotidiano do trabalho.

\section{MÉTODOLOGIA}

Desataca-se que, após a aprovação pelo Comitê de Ética em Pesquisa da Universidade Estadual do Oeste do Paraná (Parecer $\mathrm{n}^{\mathrm{o}}$ 1.621.139), juntamente com a 
Autorização outorgada pela Secretaria Estadual de Educação do Estado do Paraná SEED/PR, acrescido do Termo de Consentimento Livre e Esclarecido (TCLE), o estudo foi desenvolvido por meio de pesquisa de campo, na dimensão qualitativa de forma exploratória.

A referida pesquisa teve como públicos-alvo professores que atuam na rede pública estadual do município de Cascavel/PR, vinculados ao Núcleo Regional de Educação (NRE).

No que diz respeito à pesquisa de campo, foi efetivada por meio de entrevistas, as quais foram realizadas no período de junho à julho de 2016. Destaca-se que, as entrevistas foram guiadas por questões discursivas que abordaram aspectos relacionados como: Afastamento do trabalho com frequência por motivo de adoecimento; Já trabalharam sentindo-se doente e; O cotidiano de trabalho exerce alguma influência na sua saúde e ou doença.

Quanto aos critérios de inclusão, foram selecionados professores que atuam na rede pública estadual do município de Cascavel/PR, de diferentes regiões da cidade.

Posteriormente, foram selecionados os colégios sendo 1 (um) colégio de cada região da cidade (Norte, Leste, Sul. Oeste e Central), totalizando 5 (cinco) colégios com maior número de alunos matriculados $\mathrm{e}$, foram entrevistas 3 (três) professores em cada um destes colégios, perfazendo um total de 15 (quinze) professores.

Todos com carga horária mínima de 20 horas semanais, vínculo empregatício no Quadro Próprio do Magistério (QPM) ou de Processo Seletivo Simplificado (PSS), compondo a amostra de professores voluntários, que aceitaram assinar o Termo de Consentimento Livre e Esclarecido (TCLE) e que tinham disponibilidade de horário para participar da entrevista.

Referente aos critérios de exclusão foi considerado: Carga horária inferior a 20 horas semanais; Cargos de coordenação e Recusa em assinar o TCLE.

É oportuno destacar que, para assegurar $\mathrm{o}$ anonimato foram aplicados codinomes P1 até P15, numa ordem naturalmente conseguida pela sequência das entrevistas realizadas.

Após o processo de transcrição das entrevistas, elas foram ordenadas e categorizadas pautadas na técnica de Análise de Conteúdo, tal como propõe os autores ${ }^{2}$, correlacionado os dados com a revisão de literatura.

\section{RESULTADO E DISCUSSÃO}

No intuito de fomentar a discussão sobre o tema desta dissertação, fomos a campo para entrevistar professores do ensino médio que atuam em escolas públicas do município de Cascavel/PR/Brasil e, para isso, foi selecionada uma amostra de 15 (quinze) professores.

Discorrer sobre saúde e doença no cotidiano do trabalho docente constitui um campo complexo e desafiador. Ressaltamos que não encontramos, na literatura, um limiar entre saúde e doença, mas uma relação entre ambas. Assim, portanto, não há como mencionar uma sem falar da outra.

Nessa perspectiva, ao indagar nossos entrevistados sobre se o cotidiano de trabalho influenciava no processo saúde e doença, foi possível perceber que a dinâmica de trabalho desses profissionais tem provocado agravos à saúde. Para exemplificar esse contexto, citamos as seguintes falas: "Sim, pois as tensões do cotidiano são frequentes na sala de aula, além da desvalorização profissional e das políticas públicas ameaçadoras [...]" (P4). "O ritmo que a profissão de professor exige, é muito intenso, físico e mentalmente. Temos que nos dedicar com preparações $e$ repasse de conteúdo, requer muita habilidade e isso leva a um desgaste físico e mental, que influencia no processo de adoecimento" (P11). "[...] tratando da área da educação, o desgaste mental é o primeiro a ser sentido e com ele vêm dores de cabeça, estresse, dores musculares pela tensão que existe no dia a dia em uma sala de aula" (P15).

Diante disso, podemos inferir que o cotidiano de trabalho dos professores influência sobremaneira o processo saúde e 
doença. Uma vez que, o ambiente laboral exige dos professores habilidades físicas, cognitivas e afetivas em escala acima do normal para que possa dar conta de suas atividades, suscitando uma sobrecarga física e mental, precipitando o processo de adoecimento $^{3}$.

As circunstâncias do cotidiano, em sala de aula, sob as quais os professores se movem para concretizar as atividades, exigem muito esforço, o que muitas vezes, pode acarretar sobrecarga de trabalho. Esse fenômeno pode trazer prejuízos para a saúde da pessoa.

Embora muitos professores consigam desempenhar suas funções e manterem-se bem dispostos diante da manutenção cotidiana de sobre-esforços, outros já não têm a mesma habilidade e acabam adoecendo - condição que está atrelada à capacidade de cada indivíduo para contornar os obstáculos profissionais do cotidiano. O professor P6 declara que: "O ambiente em que atuo é hostil, cheio de adversidades e embates diários" (P6).

Nota-se, nesse relato, que o cotidiano escolar está envolto de certa ambivalência, que, por vezes, é responsável pela autorrealização pessoal e profissional, e, em outras, agente causador de adoecimento.

Observa-se, por meio da fala dos entrevistados, que a dinâmica de trabalho, na maioria das vezes, é desfavorável. Logo, se esse ambiente é prejudicial, insalubre, consequentemente desencadeará situações que alteram o equilíbrio mental, físico e social do professor. Exemplo disso é o seguinte relato: "[...] durmo pouco, fico estressado pelo barulho na sala de aula, tenho pouco tempo para lazer [...]" (P9).

Quando pensamos nas necessidades básicas de vida do ser humano, o sono é algo primordial para a sobrevivência, pois é uma condição biológica indispensável para a restauração física e mental do indivíduo. Assim, portanto, variações no padrão do sono podem provocar perturbações biopsicossociais. Mesmo sabendo da importância do sono para a saúde, muitas vezes as pessoas, a exemplo do professor acima, não conseguem dormir o suficiente, devido à jornada de trabalho que fazem.

Essa realidade presente no cotidiano dos professores está acrescida do perfil do trabalho docente, pois que, na maioria das vezes, lecionam em várias turmas, em mais de uma escola e ainda levam trabalhos e provas para corrigir em casa. Isso tudo faz o professor restringir o tempo de dormir em função das atividades de que precisa dar conta. Segundo um dos entrevistados, " $O$ ritmo que a profissão de professor exige, é muito intenso, física e mentalmente. [...] requer muita habilidade e isso leva a um desgaste físico e mental, que influencia no processo de adoecimento" (P11).

Quando o ambiente de trabalho se torna fonte de desequilíbrio biopsicossocial e suscita uma sobrecarga psíquica sem a possibilidade de mecanismos de escape, então leva o indivíduo ao sofrimento e, consequentemente, ao adoecimento ${ }^{4}$.

Situações desse teor têm aumentado cada vez mais o número de professores afastados $^{1}$, podemos inferir que todos esses fatores impactam negativamente a capacidade laboral dos professores, além do grau de tensão a que o indivíduo fica exposto constantemente. Este entrevistado diz que: "[...] o desgaste mental é o primeiro a ser sentido e com ele vêm dores de cabeça, estresse, dores musculares pela tensão que existe no dia a dia em uma sala de aula" (P15).

Percebe-se que, devido à tensão, surgem outros problemas, como dores de cabeça e musculares, atrelados ao desgaste mental e físico. A tensão, à qual o entrevistado P15 se refere, juntamente com o acúmulo de atividades, pode levar o indivíduo a excitação e a angústias, sintomas que, se não forem autocontrolados, são fontes geradoras de adoecimento.

Destaca-se que, ao questionarmos os professores sobre se eles já trabalharam sentindo-se doentes, $100 \%$ dos entrevistados disseram que "sim". Situação preocupante que suscita reflexões sobre o processo saúde e doença e o desempenho deste profissional em sala de aula, considerando que, alguns se afastam de suas atividades, enquanto outros 
raramente se afastam ou nem se afastam, como o demonstram os dados abaixo:

Gráfico 1 - Você se afasta do trabalho com frequência por motivo de adoecimento, por quais motivos?

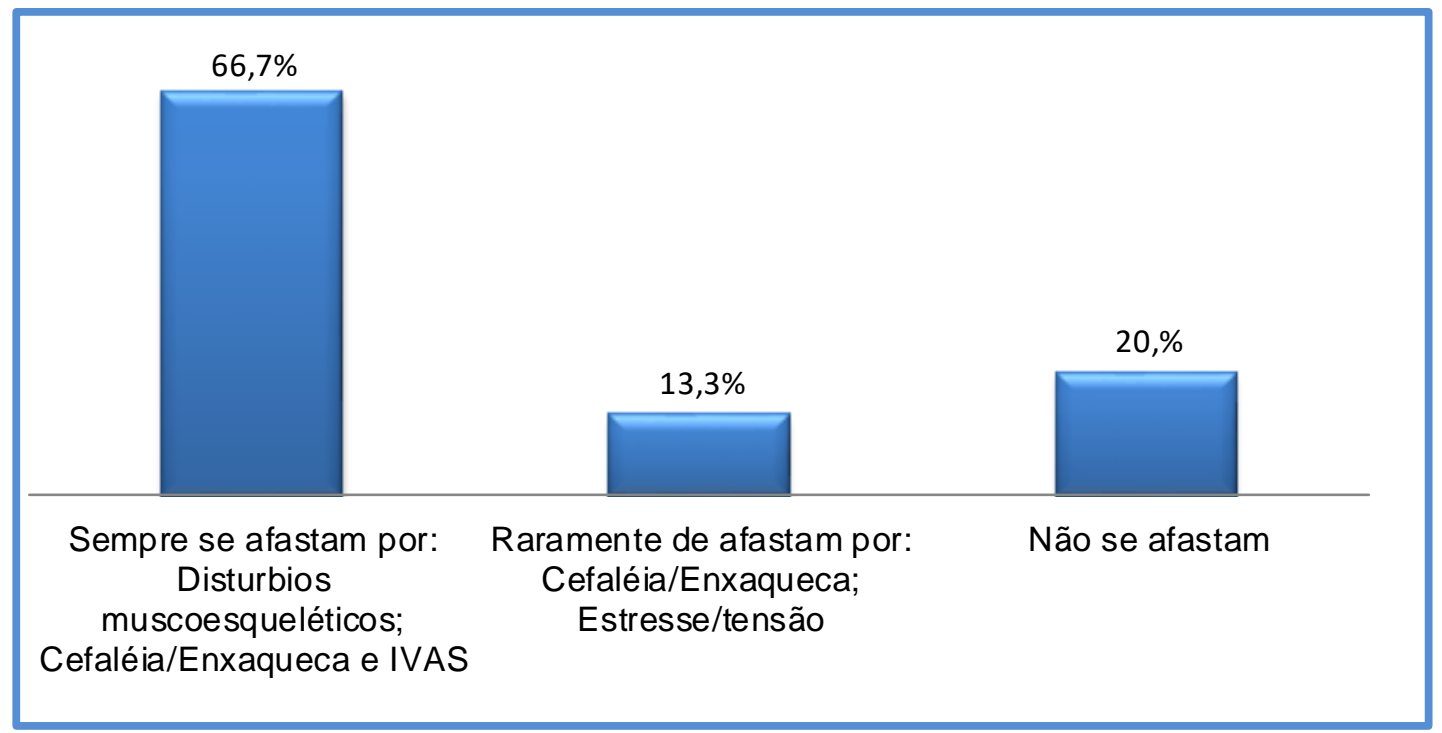

Nota: IVAS: Infecção das Vias Aéreas Superiores.

Fonte: dados da pesquisa, 2018.

Como não é possível mensurar objetivamente o quão apto está o profissional para desenvolver suas atividades laborais quando doente, então a decisão de faltar ao trabalho é uma atitude difícil de ser enfrentada. Trata-se de uma tomada de decisão efetivamente fatigante, pois, na maioria das vezes, o profissional se sente obrigado a trabalhar mesmo doente, em especial quando pensa, por exemplo, nos seus compromissos de ordem financeira e na estabilidade profissional.

Essa dubiedade, de trabalhar ou não quando está doente, pode gerar um estresse para além da capacidade psicológica e fisiológica do ser humano e, assim, contribuir para o desencadeamento de outros fatores que prejudiquem a saúde.

Diante dos dados acima, nota-se um percentual alto de professores que sempre se afastam das atividades laborais, enquanto que outra parcela não se afasta, o que denota que eles trabalham mesmo doentes. Cenário que há 15 (quinze) anos já era sinalizado ${ }^{5}$ :

"O estudo das relações entre o processo de trabalho docente, as reais condições sob as quais ele se desenvolve $e$ o possível adoecimento físico e mental dos professores constituem um desafio e uma necessidade para se entender o processo saúde-doença do trabalhador docente e se buscar as possíveis associações com o afastamento do trabalho por motivo de saúde". 5:180

Salienta-se que, a desarmonia entre corpo e mente pode ser um disparo no gatilho para uma série de eventos patológicos. As causas de afastamentos relatadas pelos nossos entrevistados são diversas, queixas similares também foram encontradas em outros estudos, como": "O Estado do Paraná tem aproximadamente 80.000 (oitenta mil professores cadastrados na rede) e, por ano, 12.000 (doze mil docentes) são afastados das suas funções por motivos de doença. [...] os fatores que mais impedem as atividades dos professores são: alterações do sistema osteomuscular e tecidos conjuntivos, lesões tanto em membros superiores como inferiores ou transtornos mentais $e$ de comportamento". 1:12

Refletindo no contingente de professores do nosso país e no que a literatura demonstra referente aos agravos a saúde desses profissionais, faz-se necessário que ações em saúde sejam amplamente difundidas e compartilhadas. Para tanto, entendemos que é preciso melhorar as articulações entre o campo da saúde e o da educação, fomentando ações que visem à conscientização, à 
promoção e prevenção à saúde dos professores.

Diríamos que as relações entre o desempenho das atividades docentes e o processo de saúde e doença se mostram multifacetadas e, um dos caminhos que nos permite trilhar é a busca de ações que visem diminuir problemas desencadeados por situações relacionadas ao ambiente de trabalho, que podem resultar em agravos a saúde.

\section{CONCLUSÃO}

É oportuno ressaltar que o professor que hoje se encontra em sala de aula não é o mesmo de ontem. Inclusive a escola e a sociedade também mudaram. Inferimos que é imprescindível tecer novas reflexões que tragam à tona os fatores relacionados à precarização do trabalho docente e, consequentemente, ao processo saúde e doença desses profissionais, visando à saúde do trabalhador.

A análise dos dados informativos obtidos junto aos docentes entrevistados, a princípio, permite afirmar que os professores têm enfrentado inúmeras adversidades para desempenhar as suas atividades. Trata-se de circunstâncias que trazem malefícios para a vida de cada professor e que repercutem na sua vida profissional, pessoal, familiar e social, gerando sofrimento e, consequentemente, um processo de adoecimento.

Outro viés que a nossa pesquisa apontou é de que, a categoria docente em questão está adoecida, pois, os professores entrevistados citaram que já foram para a sala de aula doentes e que, por vezes, tiveram que se afastar das atividades laborais.

Diante do exposto, podemos assinalar que os agravos a saúde parecem ser bem mais complicados do que se pensa, pois, na maioria vezes, como notamos nesta pesquisa, o professor, mesmo doente acaba desempenhando suas atividades pedagógicas. Nessa lógica, além de trazer mais danos à sua saúde, essa dinâmica também pode causar prejuízos no processo de ensino e aprendizagem pelo qual é responsável na escola.

\section{REFERÊNCIAS}

1. Schuster M. Corpo e adoecimento na percepção docente. Dissertação (Mestrado em Educação). Programa de Pós-Graduação Stricto Sensu em Educação. Universidade Estadual do Oeste do Paraná/Unioeste, Cascavel/PR; 2016. [online] [Acesso 2017 Mar]. Disponível em: http://tede.unioeste.br/bitstream/tede/3330/5/ Marcieli_Schuster2016.pdf.

2. Bardin L. Análise de conteúdo. Lisboa: Edições 70; 1997.

3. Pontes FR, Rostas MHSG. Precarização do trabalho do docente e adoecimento: COVID19 e as transformações no mundo do trabalho, um recorte investigativo. Revista Thema, 2020;18(Especial):278-300. [online] [acesso 2020 Dez.] https://doi.org/10.15536/thema.V18.Especial. 2020.278-300.1923.

4. Dejours C. A loucura do trabalho: estudo de psicopatologia do trabalho. São Paulo: Cortez/Oboré; 1992.

5. Gasparin SM, Barreto SM, Assunção AÁ. O professor, as condições de trabalho e os efeitos sobre sua saúde. Educação e Pesquisa, São Paulo, 2005;31(2):189-199, Ago. [online] [Acesso 2017 Fev.]. Disponível em: https://www.scielo.br/pdf/ep/v31n2/a03v31n2 .pdf. 